\title{
Some thoughts on the role of social sciences in the agricultural research centres in developing countries
}

\author{
D. B. W. M. van Dusseldorp
}

Department of Rural Sociology of the Tropics and Subtropics, the Agricultural University, Wageningen, the Netherlands

Accepted: 29 August 1977

Key words: rural development; agricultural research; social sciences

\section{Summary}

In the last decade 'integrated' rural development focusing on improving the position of the rural poor, has received considerable attention. Sometimes, however, it is overlooked that in the future, rural development will rely on agricultural development. This agricultural development depends on the results from research programmes of agricultural research centres. During agricultural research relatively little attention is paid to the effects that the implementation of the research results will have on society. This can be illustrated by the fact that for every thousand scientists at agricultural research centres only one is a permanently assigned sociologist or cultural anthropologist. There seems to be a need for more social scientists in agricultural research centres. At the same time, attention must be paid to how the technical and social sciences can cooperate with each other.

Four approaches are described, indicating how the social sciences can be integrated into agricultural research:

- the accommodating approach, in which social sciences enter when the agricultural research has produced results;

- the steering approach, in which social sciences are introduced at the beginning of the agricultural research;

- the farming system approach, in which special attention is paid to integrating various new crops and crop technologies into one farm type (horizontal integration); - the commodity approach, which focuses on the consequences of changes in crops or crop technology at each stage of production from sowing to harvesting, processing and consumption (vertical integration).

Finally, a relational framework is suggested that, if properly adjusted, could expedite the establishing of a communication pattern between the social and technical disciplines during the commodity approach. 


\section{Introduction}

Interest in integrated rural development, focusing particularly on improving the conditions of the rural poor, is growing. Integrated rural development is an extremely complicated process differing from area to area and closely interrelated with overall national development. But however varied integrated rural development may be, agricultural development, and this is sometimes overlooked, will remain its main driving force in the future.

How and in what direction agricultural development will take place will be considerably influenced by the results from agricultural experimental stations.

In the past, these stations have achieved remarkable results. Spectacular increases in yields of wheat, maize, rice, etc. have been achieved by developing new varieties and crop technologies ${ }^{1}$. Most of these innovations, however, require a high level of inputs, a well controlled production environment and considerable capacity for management. This means that these 'new crops' and their related crop technologies can only be introduced with some success in a limited number of areas and by the relatively few farmers who already have some wealth and education. In many countries this has resulted in a spectacular increase in inequality between rural regions and between farmers. This is not meant as a criticism of the agricultural experimental stations, but it indicates the terrible dilemma that they face. On one hand they have to develop crops and crop technologies that will enable agriculture to produce the food desperately needed by the growing urban and rural population. On the other hand most crops and crop technologies that can guarantee a quick rise in world food production tend to drive the poorer part of the rural population out of agriculture at the very time that the development of secondary and tertiary sectors cannot absorb them.

How to solve this problem is beyond the scope of this paper. But the fact that results from agricultural experimental stations can contribute decisively to world food production but can simultaneously create massive social and economic problems that will adversely affect hundreds of millions of poor rural inhabitants, raises the question whether the social sciences should not play a greater role in the work done at these stations. On the basis of FAO statistics and my own observations, I have calculated that the ratio of sociologists and cultural anthropologists permanently assigned to agricultural experimental stations to scientists from other disciplines currently is less than $1: 1000$.

Given that the introduction of new crops and crop technologies can profoundly influence the social and economic structure of rural areas, it seems obvious that one of the prerequisites for succesful integrated rural development (which aims to improve the condition of the rural poor) must be an awareness of the social implications of such agricultural innovation. Therefore, social scientists should be employed at agricultural experimental stations to help formulate agricultural devel-

1 Crop technology comprises all aspects of crop husbandry from land preparation and sowing to harvesting, storage and processing. What is said subsequently for crops and crop technologies also hold true for cattle and cattle management systems. 
opment strategies. However, introducing social sciences ${ }^{2}$ into agricultural experimental stations causes problems, because social sciences differ from the technical and biological sciences in thought processes, approach to research and in language.

\section{Could social sciences have a function in agricultural research centres?}

The first question that can be asked is, what can sociology and cultural anthropology contribute to the development of new crops and crop technologies: do these sciences have a function within the framework of agricultural research institutes? (Cancian, 1977; Werge, 1977.)

In many societies, agriculture is not only a way of earning a living but is also a way of life. Existing agricultural practices are embedded in the social and economic structure and surrounded by cultural and religious activities. Changing agricultural practices, by introducing new crops and/or crop technologies, will often result in changes in the social and economic structure, in religious activities, in cultural values etc. that can be functional as well as disfunctional for the various groups in the rural societies.

It therefore seems important to ascertain in advance what effects the development and introduction of new crops and/or crop technologies, could have on the existing social and economic situation.

Knowledge of the existing pattern of leadership, power structure, size and structure of families, division of labour according to sex and age, marketing patterns of local and regional levels, the calendar of social and cultural events, food habits, ergonometric aspects of agricultural activities etc. can be used to indicate the properties that new crops and crop technologies should have. New crops and crop technologies evolved with the needs of a particular rural society in mind would be more readily accepted, and should be beneficial or at least not disfunctional for the poor and weak groups of rural communities.

Even without becoming more specific it seems clear that social sciences can and should play a role in agricultural stations.

\section{Some reasons why social sciences are not easily accepted in agricultural research centres}

It is amazing that in agricultural research centres, institutions with a long tradition of interdisciplinary research patterns, social sciences are practically non-existent. Why are sociologists and cultural anthropologists seldom invited to the sanctuary of agricultural research? The following observations may explain this.

- One of the reasons why sociologists are not taken very seriously by the technical and biological disciplines is that they do not produce hard facts and universal laws comparable to those produced in, for instance, the physical and chemical sciences. This is undeniable and will remain so because of the nature of social sciences. First

\footnotetext{
${ }^{2}$ By 'social sciences' is meant sociology and cultural anthropology, and also social psychology, public administration sciences etc.
} 
of all, social scientists have to reckon with a tremendous number of variables, all interrelated and sensitive to changes in time and/or situation. They are seldom able, often for ethical reasons, to conduct experiments in which it is possible to isolate specific variables. Therefore sociological research always takes a long time to obtain hard facts and theories. But even in ideal conditions, sociology can seldom formulate a law, simular to the law of gravity, that remains valid over a long period of time and among many different conditions. However, compared to other disciplines, such as the biological disciplines, the position of social science is not as different as is often assumed. However, social sciences are often rather reluctant to formulate, even tentatively, 'middle range theories' (see Merton, 1967). It is important that they should lose at least some of their modesty without losing touch with their scientific conscience.

- Another reproof sociologists often have to face is that many of the results from sociological research are facts or theories that, at first sight, could have been perceived by laymen. It is true that persons gifted with social insight can very often make assumptions that are subsequently confirmed by sociological research. But there is a considerable difference between assumptions and proven facts. It is often forgotten that sociological research has also disproved assumptions that were believed in by many people.

- The 'jargon' used by sociologists is often disliked by other, particularly technical, disciplines. It must be realized that all disciplines use a certain type of jargon. Sociologists have to face the problem that the scientific questions they want to study are frequently everyday problems familiar to many persons. However, the terminology used to describe these problems is seldom clear cut and many words have several connotations. In order to avoid confusion the sociologist is forced to use different words that, at first sight, describe the same phenomena that are normally indicated by 'simpler' words.

- Sociology is too close to politics. This is a common misunderstanding. Sociology often directs its attention to problems easily recognized as having political significance. But the same holds true for nuclear physics, biochemistry, virology, and plant breeding. The plant breeder who develops a sugar cane variety that maintains its sugar content after maturity much longer than other varieties, is introducing an important political factor. For instance, the negotiating position of directors of sugar cane plantations will be strengthened vis-à-vis labourers or labour unions in situations where sugar is produced in a plantation system. At the same time, this sugar cane variety could increase farmers' income in areas with small farmers because more sugar cane can be grown with the same amount of labour because the harvest period is longer. Similarly, soil scientists preparing land classification maps indicating areas suitable for irrigation can produce political dynamite when these maps are used for negotations concerning the division of water in a certain river basin that belongs to several countries. Sociology is as political or as non-political as most other sciences. There remains, however, the fact that, unlike physics or chemistry, sociology analyses a part of the environment in which most individuals, including the sociologist, are consciously involved. This makes it more difficult for sociologists, compared to other scientists, to remain unbiased. But it has to be realized 
that so-called value-free research is as impossible for sociologists as for biologists or any other scientists.

- It often takes sociologists a long time to produce the results of their field work. This reproof is very serious, considering how sensitive social findings are in relation to time. It is therefore very important for the social sciences to develop techniques that make it possible to shorten the time between field research and the interim or final reports containing the findings of this field research. During their training, it should be impressed upon sociologists not only that time is money but also that speed in producing reports is essential to prolong the validity of their findings.

From the foregoing remarks it becomes clear that at least some of the allegations made against sociologists are also true for other disciplines. However, there are certain aspects in the scientific behaviour of sociologists that should be improved or changed in order to make them more acceptable for work in agricultural research stations. In general, a sociologist working alongside technical disciplines should be capable of:

- delivering his field findings in a reasonably short period;

- formulating at least tentatively 'middle-range theories' that are important for rural development and relevant for the research project;

- formulating his findings in a language understandable by the technical and biological disciplines;

- developing enough knowledge to understand the findings of technical and biological disciplines and their relevance for his own science, and developing a certain understanding for the problem other disciplines face in their research programmes. It goes without saying that these capabilities should be possessed by all scientists working in agricultural research stations.

From the foregoing it becomes clear that certain changes are required in the curricula of most faculties of social sciences in order to produce sociologists who are capable of operating efficiently in agricultural research centres.

\section{Various approaches towards integrating social sciences in research programmes of agricultural research centres}

Because of the absence of social sciences in agricultural research centres, little experience has been obtained on how the technical/biological disciplines can and should cooperate with the social disciplines in an interdisciplinary research programme. Taking into account the different ways of thinking, approaches and working methods between the disciplines, this cooperation requires special attention and preparation.

It must be emphasized that this paper only deals with social research that contributes directly to the social aspects of new crops and crop technologies. I am not suggesting that agricultural research stations should conduct sociological research in general and should develop, for instance, rural sociology. This should be the task of other research institutes, departments of sociology in agricultural faculties of universities, etc. National and international research councils must provide governments with proposals on which research policies can be based that will result in a 
'balanced body of knowledge' relevant for planned rural development.

However, information on the socio-economic environment can only be incorporated into agricultural research if the staff of agricultural research stations includes social scientists (either sociologists/cultural anthropologists and economists, or persons well versed in all three disciplines). The main task of these scientists is to introduce existing knowledge of the socio-economic environment and integrate this into the research programmes directed towards the development or improvement of crops, crops technology, types of cattle and management systems, that will contribute to rural development.

Hereafter an attempt is made to indicate various approaches that could facilitate the integration of the social sciences in agricultural research. The approaches differ from each other according to when the social sciences are introduced in the agricultural research.

a) In the accommodating approach, social sciences enter as soon as the agricultural research has produced results.

b) In the steering approach, social sciences are introduced at the beginning of the agricultural research.

Approaches can also be distinguished from each other according to whether emphasis is given to crop or to farm type.

c) In the farming system approach, special attention is paid to the integration of various new crops and crop technologies into one farm type (horizontal integration).

d) In the commodity approach, the focus is on a special crop or crop technology and its socio-economic consequences. One can also say that in this approach special attention is paid to vertical integration.

Each approach has its advantages and disadvantages and requires its own working methods. The approaches overlap considerably and should be used in a certain mix, depending on the specific problems an agricultural research station is supposed to solve.

The various approaches will now be discussed in more detail.

The accommodating approach. In this approach the social and economic disciplines are not involved until the technical disciplines have developed a crop and/or crop technology or a type of cattle and/or cattle management system. Once this knowledge is available, the social and economic disciplines must ascertain the socioeconomic consequences of implementing the new findings; and how the farmer, his family and the socio-economic infrastructure must be adapted in order to guarantee the success of this implementation.

One of the problems with this approach is that in many cases it is very difficult to assess the socio-economic consequences of new findings. This requires close cooperation between the socio-economic, technical and biological disciplines. In this approach cooperation is not always easy to establish because the socioeconomic disciplines have not participated in the research programme and are therefore not (or not sufficiently) acquainted with the technical properties of the new crops or crop technologies that have been developed.

Another problem is that the technical disciplines have sometimes taken 5-10 years 
to develop or improve crops or types of cattle with their related management systems. When results are promising from a technical point of view, sociologists and economists get only little time to study the anticipated social and economic impact of the new findings on rural society. This problem worsens when overall knowledge of the socio-economic aspects of the relevant rural society or part of it is limited or even non-existent.

Often this results in the new findings, after a short period of testing that is sometimes confused with demonstration, being given to the extension service for dissemination among the rural population, which is then left to cope with socioeconomic side-effects that may not have been anticipated.

The socio-economic effects of new findings have to be assessed at two levels: - at the macro (national) and meso (provincial, district) level, indications must be obtained of the effect of the new findings on the social, administrative and economic structure;

- at the micro (local) level an assessment must be made of the effects on the individual farm, farmer and his family and on the social structure and power balance in the local community.

In this approach, one expects that when dysfunctional socio-economic side-effects occur, measures can be developed in time to prevent the rural population being seriously disadvantaged. Practice shows that this is often not possible and it is mostly the rural poor who have to bear the burden resulting from these side-effects. When time is short this information cannot be gathered on an a priori basis and must be collected on a post facto basis via active research in close cooperation with extension services and backed up by the various disciplines at the research stations.

It is sometimes argued that this approach does not make it necessary to include social sciences in agricultural experimental research stations, for these social sciences could be located in agricultural extension services. But it is well-known that the transmission of technical findings from research stations to extension services is seriously hampered by difficulties in communication between them. The location of social sciences in both institutions could improve this by contributing on the one hand to speedier transfer of knowledge and on the other hand to knowledge that is better adapted to the different 'felt needs' of the various groups of the rural population.

The steering approach. This approach can work as follows. A careful analysis of the rural society results in indications of the properties that crops or cattle breeds and their related management systems must have for integrated rural development with special attention to the weaker groups of rural society. On the basis of this information, which should be used in the same way as the available knowledge on the natural environment, the research programme of the agricultural research stations can be designed.

To make this approach feasible, attention must be paid to the following points. - Considerable knowledge of the processes relevant for rural development must be available. This knowledge must not only be available for the local level via farm and village studies but also for the meso and macro levels. Studies such as Polly 


\section{B. W. M. VAN DUSSELDORP}

Fig. 1. Relational framework for crop A.

(Some) components and processes of the physical and biological environment
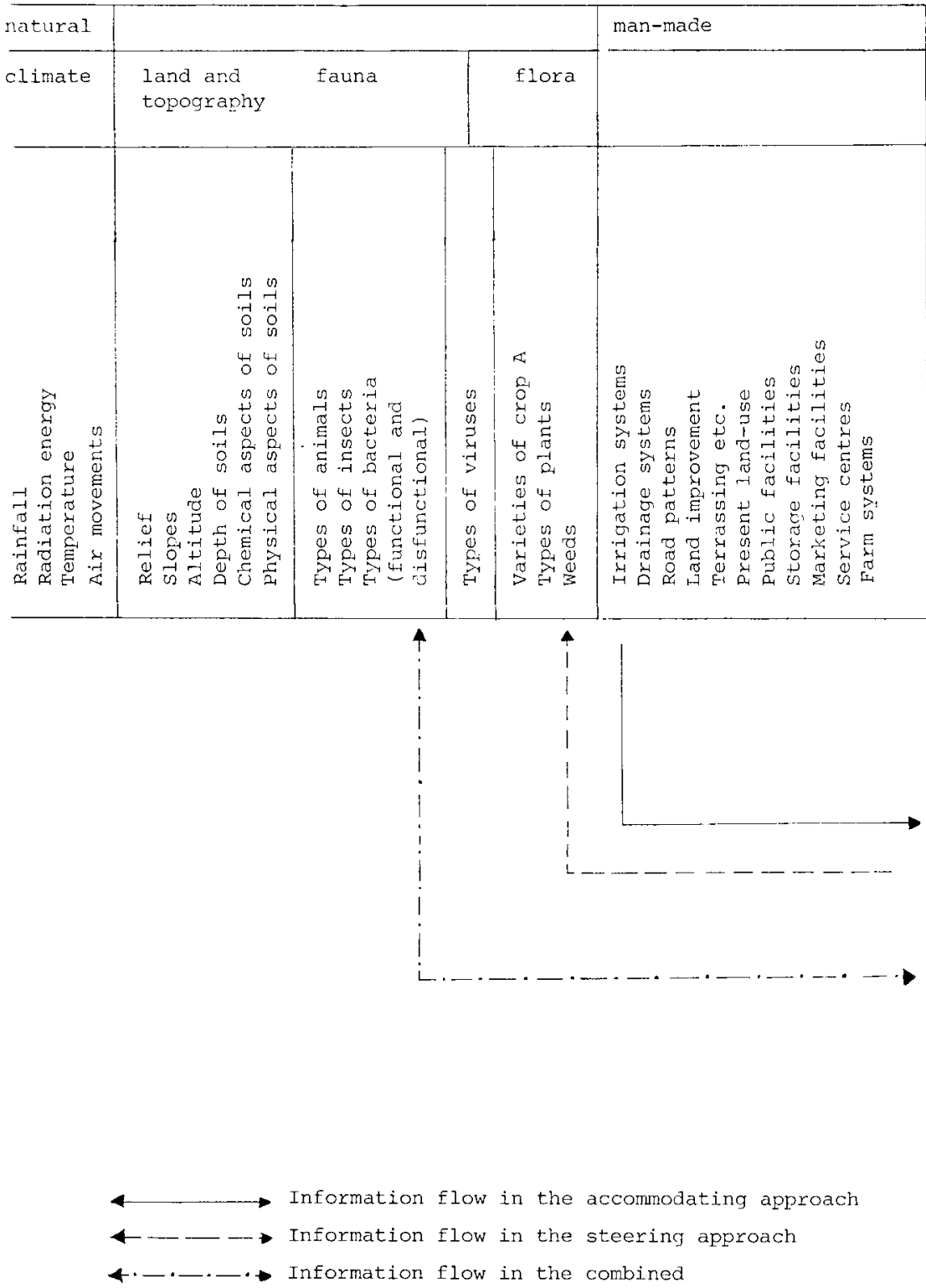

Information flow in the accommodating approach

Information flow in the steering approach

Information flow in the combined

accommodating/steering approach
(Some) activities belonging to the $c$ technology of crop

Larda reclamation Land preparation Erosion control Irrigation activities Drainage Sowing Transplanting weeding Crop protection Pruning Harvesting Transport (on far Storage (on farm) Processing (on $\mathrm{fa}$ Marketing

(farmers/market) Transport Storage

Processing Distribution Preparation (food crops) seed

Fertilizer/manure Manuring Insecticides crop protection Farm equipment 
(Some) components and processes of the social and economic environment

\begin{tabular}{|c|c|c|c|c|c|c|c|c|}
\hline $\begin{array}{l}\text { Cultu- } \\
\text { ral \& } \\
\text { reli- } \\
\text { gious }\end{array}$ & $\begin{array}{l}\text { Kinship } \\
\text { systems }\end{array}$ & $\begin{array}{l}\text { Socio- } \\
\text { economic } \\
\text { systems }\end{array}$ & $\begin{array}{l}\text { Labour } \\
\text { division }\end{array}$ & $\begin{array}{l}\text { Polit- } \\
\text { ical } \\
\text { systems }\end{array}$ & $\begin{array}{l}\text { Food } \\
\text { habits \& } \\
\text { patterns }\end{array}$ & $\begin{array}{l}\text { Management } \\
\text { capacities }\end{array}$ & \multicolumn{2}{|l|}{$\begin{array}{l}\text { Social } \\
\text { change }\end{array}$} \\
\hline 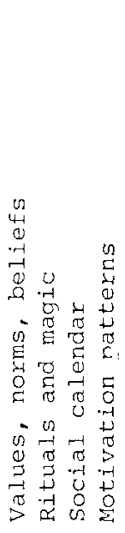 & 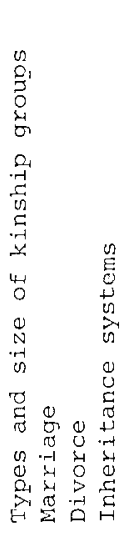 & 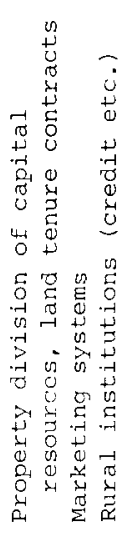 & 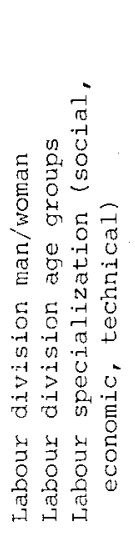 & 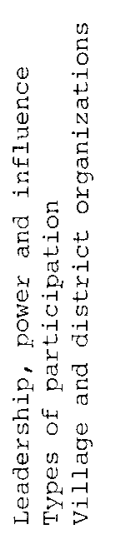 & 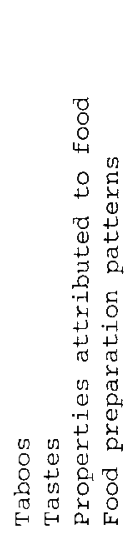 & 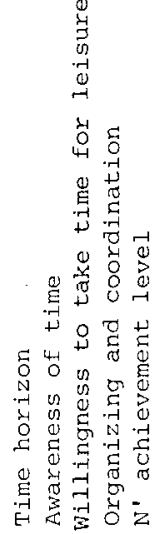 & 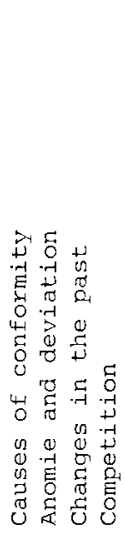 & 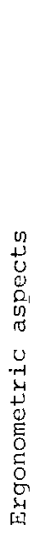 \\
\hline
\end{tabular}


Hill's 'Migrant cocoa farmers of Southern Ghana' (1963) and Galleti, Baldwin \& Dina's 'Nigerian cocoa farmers' (1956) are important building stones. They should, however, be followed up as soon as possible by studies like Sara Berry's 'Cocoa, custom and socio-economic change in rural Western Nigeria' (1975). Such studies could lay the foundation for the 'middle range theories' that have to be developed, at least tentatively, before it becomes possible to indicate the contribution technical findings and their related consequences could have on rural development.

- Even in the first stages of the steering approach, close contact should be established between the socio-economic and technical disciplines. By mutually exchanging information they can influence and steer each other's research programmes.

The steering approach is seldom used in agricultural experimental stations. This is mainly because systematic insights into the major socio-economic mechanisms controlling rural development are seldom available, and if available they are not explicitly related to technical aspects of rural development. Secondly, when this information is available, it is either unknown or unused at agricultural research stations because there are no social scientists on the staff.

The steering approach can only be effective if social research is done outside agricultural research stations to produce middle range theories concerning rural development, and if there are social scientists on the staff of these stations who are able to channel the resulting information correctly into the various agricultural research programmes. In the past social sciences, especially the economic sciences, have had a certain steering influence on the research programme of agricultural experimental stations via agricultural sector plans. In these plans certain production goals are indicated that can be translated into research objectives for agricultural experimental centres. This has often resulted in too great an emphasis on export crops and lack of attention on food crops for home consumption. Nowadays, more attention is paid to research programmes that will improve the food situation. However, the indications given by the social and economic sciences in agricultural sector plans are too general to effectively guide the design of research programmes to develop crops and crop technologies that not only result in increased production but also guarantee a fair chance to the rural poor to improve their lot. To do this social disciplines must also be represented in agricultural research stations, and whenever possible be partly integrated in research programmes via the steering approach.

The farming system approach. Several international agricultural research stations have used this approach (also called horizontal integration), which concentrates on the social, economic and technical consequences of the introduction of new or improved corps or types of cattle and their related management systems on the various relevant farming systems. This approach can also be used to indicate, on the basis of the existing farming system, the properties that new crops and crop technologies to be developed by agricultural research centres must have to guarantee their successful introduction. The technical, economic and social changes that might result can also be ascertained. This, however, should be done in an interdisciplinary and comprehensive way. Too often sociologists and economists carry out their re- 
search on farming systems separately from the technical discipline. This makes it difficult if not impossible to interrelate the various findings and to obtain an overview of the existing farming systems.

The farming system research programme must also have a historic component. Often this type of research merely gives a static analysis of the actual situation. However important this information is, it is not enough to be used in research programmes directed towards the improving the existing farming system. It could also give the misleading impression that 'traditional farming systems' are stable. In certain cases this is certainly true: there are many farming systems that have hardly changed for centuries. In many other farming systems, however, there is much more dynamism than is often realized. The transition from one farming system to another should also be carefully studied.

Longitudinal studies are necessary in order to assess the capacity of a farming system to absorb innovations. These studies are often difficult to realize because historical data are lacking. There are often, however, much data hidden in the archives of governments and private agencies (and not only within the ministry of agriculture) that are often overlooked.

The commodity approach. This approach (vertical integration) tries to assess the socio-economic consequences of research-developed crops (or livestock) at each stage of production starting from breeding, tilling, sowing, harvesting, etc. until the last steps such as transport, marketing, storing, processing, food preparation and consumption. Knowledge of the social, economic and technical aspects of the production system of a commodity can be used to indicate which properties will guarantee a crop or crop technology's successful introduction and the improvement of the position of small-scale producers and poor consumers.

The first part of this approach overlaps with the farming system approach. Therefore a combined commodity-cum-farming system approach is advised. The latter stages of production of a commodity are not always within the research responsibilities of an agricultural research centre. If, for instance, transport, storing, processing or food preparation are research tasks of other institutes, a pattern of cooperation has to be developed in order to attain an integrated commodity approach. Most agricultural research stations are commodity-oriented, as far as marketing. In most cases one does not breed a new farming system but a new variety of rice or a new breed of sheep. The commodity approach is therefore a good focus for cooperation between socio-economic and technical disciplines. However, in the later stages there is a chance, as was mentioned earlier, that part of the research may be allocated outside the research station. In that case the socio-economic disciplines in agricultural research centres will have to rely on other research institutes for information on the meso and macro levels of the production process. This will complicate coordination of the commodity approach.

The various approaches for integrating social sciences in agricultural research centres are complementary, overlapping and interrelated. They should always be used in a certain mix. The exact nature of this mix cannot be spelled out in detail; 
it depends on the specific problems that have to be solved and the socio-economic situation in which these problems are found.

Some general remarks, however, can be made.

It seems that the commodity approach, especially in the first stages, provides the most logical starting point for cooperation between the biological and the social sciences. However, the farm system approach cannot be omitted because it is in the integration of a new crop or crop technology in a farm system that actual results of the new findings become available to the farmers. The emphasis given to the steering approach depends on the knowledge available to the social sciences of a certain country or region. The less sociological information and social scientists are available, the more they will have to fulfil a 'fire brigade function' in the accommodation approach.

The foregoing is a plea to give the social sciences a fair start in agricultural research and not to ask them at its very end to provide solutions in an unreasonably short period of time.

The idea that a good technology sells itself is only partly true. Too often it is assumed that farmers and their families and the socio-economic and physical infrastructure can easily adjust to new technical findings. It is true that they can adjust more easily than, for instance, topography, climate, or some biological processes. But the scope of possible changes in society is often overestimated and the time period and funds required to realize these changes are often underestimated.

In some international agricultural research stations, interesting frameworks for cooperation between the technical and social disciplines have been developed. The following example is taken from ICRISAT (International Crop Research Institute for the Semi Arid Tropics, Hyderabad, India). This institute has a set-up that makes it possible to combine the accommodation and steering approach via the farming system approach.

One department in ICRISAT investigates various farming systems with special attention to water management in micro-watersheds. As far as possible the research is done under conditions comparable to the existing farming systems. For land preparation, for instance, bullocks are used instead of tractors. Records are kept of the labour and other inputs used. The economic department (including at present a cultural anthropologist on temporary assignment) has started village studies in areas that are physically similar to the area where the technical research takes place: special attention is paid to the social and economic aspects of those components of the farming systems that are receiving special attention from the technical disciplines because they regard them as being instrumental for improving production. This set-up makes it possible:

- to compare the old and the newly emerging farming systems with each other at an early stage of the research. This comparison enables the social disciplines to concentrate their research on the ways and means necessary to adapt rural society in such a way that the changes finally proposed by the technical disciplines can be introduced with beneficial effects for all groups in the rural society (accommodating approach).

- for the socio-economic disciplines to indicate during the research process the 
major socio-economic bottlenecks to be expected if certain measures being considered by the technical disciplines have to be introduced. They can suggest adaptations that can be tested by the technical disciplines (steering approach).

- when the technical measures have been developed to a level where they can be tested on their technical correctness and socio-economic feasibility to start pilot projects there are villages studied by the socio-economic disciplines for which extensive base-line data are available.

A relational framework to expedite the coordination and integration of the research activities of social-economic and technical/biological research programmes in agricultural research centres

As mentioned earlier, cooperation between the technical, biological and socioeconomic sciences is difficult because of the great differences in the way of thinking, the way of approaching problems, research methods and scientific language.

The various approaches described above only indicate how the social and economic sciences can become involved in agricultural research. Effective incorporation of the social and economic sciences is only possible when more specific patterns of cooperation are developed. This will require a considerable amount of thought and experimentation before social scientists are involved on a medium or large scale in agricultural research centres. Otherwise the social scientists would run the risk of becoming isolated in these centres, with a good chance that after some time they would disappear from the agricultural research scene.

In the following section a relational framework is discussed, especially relevant to the commodity approach. This framework requires considerable elaboration and testing before it can be considered operational. It is meant to expedite the regulation and integration of exchange of information between the research programmes of social/economic and technical/biological scientists. During the exchange of information attention must be paid to the following:

- What kind of information can be relevant for other disciplines?

- When should this information be given in such a way that it can be understood by other disciplines?

Fig. 1 shows a relational framework:

- On one part of the horizontal axis the several components and processes of the physical environment are indicated.

- The other part of the horizontal axis shows several components and processes of the socio-economic (administrative) environment.

- On the vertical axis the various production activities and inputs are mentioned that belong to a certain crop technology of a specific crop.

The components: processes, production activities and inputs will vary from environment to environment and are specific for a certain crop or crop technology that is to be developed.

Given the physical and biological processes and components of a specific environment a certain range of crops and crop technologies can potentially be developed. When these crops and crop technologies are developed and introduced they require a certain set of production activities and inputs before they result in higher pro- 
duction or a better quality product. This often necessitates changes in existing production activities and inputs. Production activities and the access to inputs are determined by the components and processes of the socio-economic environment. It therefore seems logical that production activities and inputs are the channel through which information should flow between socio-economic and technical/ biological research programmes in agricultural research centres.

How this can be achieved is shown in the following example. If a new variety of a crop requires another crop technology (for instance, deeper tilling of the soil that cannot be done by the available human or animal power, thereby necessitating the introduction of mechanical power) the rural people who have access to capital and technical inputs will benefit. When the existing technical, economic, social and administrative infrastructure limits this access to a small group of farmers this will result in an increase of inequality in the rural society.

In an integrated rural development programme paying special attention to the poor, an accommodation approach is required in which the sociologists, economists, public administration experts etc. have to set up research programmes that will indicate how a social-economic and administrative infrastructure can be developed that will avoid the disfunctional side-effects of the new crop on the socio-economic structure of the rural society. In a policy of integrated rural development with emphasis on improving the situation of the weaker groups of society, special attention should be given to the steering approach. In this case the social and economic sciences should analyse the socio-economic environment in such a way that they can indicate what properties (production activities and inputs) a crop technology and the related crops should have in order to be specially beneficial to the small producers in a specific socio-economic structure.

It follows from the foregoing that there should be a two-way stream of information (an integration of the steering and the accommodation approaches). The indication that there is potential for the development of certain crops and crop technologies that can be beneficial for small producers provided there is a certain type of infrastructure available, will orient research, planning and implementation in the fields covered by the social and economic sciences.

On the other hand, the socio-economic research can indicate that in a specific socio-economic environment, agricultural research has to accept certain restrictions or priorities in order to avoid increasing inequality in the rural society. These restrictions should be taken as seriously by the technical and biological scientists as are the restrictions imposed by the technical and biological environment.

It is assumed that when the relational framework indicated in Fig. 1 is developed further it could be used to integrate the socio-economic and technical-biological research programmes of agricultural research centres. This could lead to findings that would contribute to the success of programmes for integrated rural development aiming at strengthening and improving the position of the rural poor.

The development of such tools is both difficult and challenging, particularly for international research centres. Cooperation between the technical and social disciplines in agricultural research stations could be achieved relatively simply by introducing the following measures: 
- Select people who are willing and capable of understaning and cooperating with persons from other disciplines.

- Organize working sessions at regular intervals where all disciplines report on the progress of their research programmes and try to indicate the relationship between their various research programmes.

- As often as possible organize field trips in which technical as well as social disciplines participate.

The discussions in the field and during travelling are likely to lead to a fruitful exchange of ideas.

It is clear that these measures, though simpler said than implemented, are essential in order to create a climate in which closer cooperation between technical and socio-economic disciplines becomes possible. However, a more systematic approach is also necessary to set this cooperation on a more scientific footing.

\section{Conclusion}

In the last decade considerable changes have taken place in the development strategies of the Third World (Jolly, 1976). The concept of economic growth no longer has the overriding role it used to have. Other elements have gained importance, such as:

- minimum requirements for family private consumption;

- essential community services;

- productive employment;

- participation.

Nowadays, a better distribution of the development results is aimed at (McNamara, 1973). And to lessen the dependance of developing countries on the rich countries and of rural areas on urban centres, growth of self reliance or self confidence (Minhas, 1976) is promoted.

The changes mentioned above must have consequences for agricultural research. It is not only the quantitative growth that counts, although this should not be neglected, but crops and crop technologies must be developed that will enable the total rural population to improve their position.

It is true that most activities necessary to obtain the objectives mentioned above (such as land reform, development of rural institutions, community development) are outside the field covered by agricultural research centres. This does not lead, however, to the conclusion often drawn by technical and biological scientists that there is no place for the social sciences in agricultural research centres. Results produced by these centres, e.g. new varieties and crop technologies, not only contribute to the increase of agricultural production, but also profoundly influence the social and economic structure of rural societies.

It is clear that in order to develop crops and crop technologies whose social and economic properties will contribute to rural development that results in redistribution with growth (Chenery, 1974), close cooperation between the technical/biological and social/economic sciences in agricultural research centres, is essential. This requires: 
- the development of cooperation patterns between the technical/biological and social/economic sciences. To begin with this could be a task for the international agricultural research centres.

- an increase in the number of social scientistis in the international, national and sometimes in the regional agricultural research centres.

- some adjustments in the attitudes and research methods of social scientists.

This should be the task of departments of (rural) sociology in the universities and faculties of agricultural sciences.

\section{Acknowledgment}

This article is a revised version of a lecture given at the International Conference on 'Rural development technology: An integrated approach', June 1977, organized by the Asian Institute of Technology, Bangkok, Thailand. The author has benefitted from discussions with: staff members from the Department of Rural Sociology of the Tropics and Subtropics, the Agricultural University of Wageningen; staff members of the International Centre for Tropical Agriculture (Cali, Colombia); the International Potato Centre (Lima, Peru); the International Crop Research Institute for the Semi Arid Tropics (Hyderabad, India) and the members of the Small Farmer Group from the International Agricultural Centre and the Agricultural University (Wageningen).

\section{References}

Berry, S. S., 1975. Cocoa, custom and socio-economic change in rural Western Nigeria. Clarendon Press, Oxford.

Cancian, F., 1977. Can anthropology help agricultural development? Culture Agric. (Bull. Anthrop. Study Group agrar. Syst.) No 2.

Chenery, H., 1974. Redistribution with growth. World Bank / Institute of Development Studies, University of Sussex. Oxford University Press, London.

Galleti, R., K. D. S. Baldwin \& I. O. Dina, 1956. Nigerian cocoa farmers. Oxford University Press, London.

Hill, P., 1963. Migrant cocoa farmers of Southern Ghana. Cambridge.

Jolly, R., 1976. Changing views on development. Paper for the symposium 'Surveys for development', organized by the International Institute for Aerial Survey and Earth Sciences, Enschede, Netherlands.

McNamara, 1973. Address to the Board of Governors. World Bank. Nairobi, Kenya.

Merton, R. K., 1967. On theoretical sociology. Collier-Macmillan Company, Toronto.

Minhas, B. S., 1976. Self-reliance Seminar. February 1976. (Quoted from Jolly.)

Werge, R., 1977. Anthropology and agricultural research: The case of potato anthropology. C.I.P. Socio-economic Unit. Stencil, Lima. 